\title{
GIS Based Mapping and Analysis of Municipal Solid Waste Collection System in Wa, Ghana
}

\author{
Hamidu Abdulai' ${ }^{1}$, Rafaat Hussein ${ }^{2}$, Eddie Bevilacqua ${ }^{2}$, Mark Storrings ${ }^{2}$ \\ ${ }^{1}$ Environmental Protection Agency, Upper East Regional Office, Bolgatanga, Ghana \\ ${ }^{2}$ State University of New York, College of Environmental Science and Forestry, Syracuse, New York, USA \\ Email: abdulaihamid@yahoo.com
}

Received 25 February 2015; accepted 20 March 2015; published 25 March 2015

Copyright (C 2015 by authors and Scientific Research Publishing Inc.

This work is licensed under the Creative Commons Attribution International License (CC BY). http://creativecommons.org/licenses/by/4.0/ (c) (7) Open Access

\begin{abstract}
Collection of Municipal Solid Waste (MSW) is important in every waste management program. Communal container collection systems appear most prevalent in many developing countries. However, this collection system is associated with problems such as overflow of waste containers, ground dumping at collection sites, and open/indiscriminate dumping at unauthorized places. The spatial distribution of these activities present potential contamination challenges to water resources. Spatial information on Municipal Solid Waste Collection/Dump Sites (MSWCS) is essential for Municipal Solid Waste Management (MSWM) decision-making, including siting and collection route planning, and dumps cleanup. Integration of Geographic Information Systems (GIS) and Global Positioning Systems (GPS) present a platform to capture, map, and analyze spatial MSWM issues. This study applied GIS and GPS technologies to map MSWCS in Wa town, Ghana. Wa Municipality waste collection system efficiency was analyzed based on spatial availability of communal containers. A GIS model was developed and used to analyze proximity of MSWCS to boreholes drinking water sources. A pollution risk map was also developed to analyze the potential impact of indiscriminate dumps on hand-dug wells and surface water in Wa. The results reveal poor management in a significant number (about 67\%) of MSWCS sites. Fifteen percent of mechanized boreholes failed the minimum proximity requirement $(\geq 100 \mathrm{~m})$ of the model. This study findings illustrate that MSWM in developing countries may be improved using GIS and GPS technologies. The approach used for Wa could be replicated in other towns in Ghana and other developing nations with similar MSWM problems to enhance policy and management decision-making.
\end{abstract}

\section{Keywords}

GIS, GPS, Municipal Solid Waste, Communal Container, Water Resources

How to cite this paper: Abdulai, H., Hussein, R., Bevilacqua, E. and Storrings, M. (2015) GIS Based Mapping and Analysis of Municipal Solid Waste Collection System in Wa, Ghana. Journal of Geographic Information System, 7, 85-94. 


\section{Introduction}

Collection of municipal solid waste (MSW) is an important step in every waste management program. It is one of the greatest challenges facing waste managers worldwide. Irrespective of the waste management method to be employed, the waste must first be collected. Collection processes may be tailored to meet the goal of the intended waste management method such as resource recovery or landfilling. MSW collection usually involves people and a means of transport to a transfer station, treatment facility, or final disposal site [1]. Collection systems may differ markedly between developed and developing nations. The concept of house-to-house is most common especially for domestic MSW collection in most developed countries [1] [2]. However, the utilization of this concept has generally been very low particularly in developing countries due to numerous challenges including financial and economic problems [3].

Communal container collection systems appear most prevalent in many developing countries [4]. In this type of system, communal containers (waste bins) are provided at vantage points within communities for households to drop-off MSW. Collection trucks then pick up containers, empty them at a final disposal site and return the containers to their locations. However, this collection system is associated with difficulties leading to uncollected waste as a result of overflow, ground dumping at collection sites, and open/indiscriminate dumping at unauthorized places. The spatial distribution of these activities present potential contamination challenges to water resources, particularly rivers/streams as well as drinking ground water sources such as boreholes and hand-dug wells.

The utilization of Geographic Information Systems (GIS) and Global Positioning Systems (GPS) to capture and analyze spatial data is well known; and is growing in municipal solid waste management (MSWM), e.g. [5]-[7]. Information on geographic locations of municipal solid waste collection/dump sites (MSWCS) can help decision-making in MSWM, including collection route planning, dumps cleanup, and future siting of collection sites in order to enhance quality of water resources. Although few studies have mapped solid waste collection systems [6] [8] and refuse dumps [4] [9], these studies failed to analyze MSW collection inefficiencies as a result of inadequate number of collection containers and associated ground dumping activities. Besides, such a study has never been carried out in Wa, Ghana. This study, therefore, applied GIS and GPS approach to identify and map MSWCS and assessed the adequacy of the communal containers collection system based on ground dumping activities in Wa, Ghana. It further analyzed the contamination potential on the ground water resources including boreholes and hand-dug water wells that may arise from inappropriate practices at the MSWCS.

\section{The Study Area}

\subsection{Geographic and Demographic Characteristics}

Located in the North-Western part of Ghana, the town of Wa (See Figure 1) is the administrative capital for Wa Municipality. The town is centrally located around latitude $10^{\circ} 3.76^{\prime} \mathrm{N}$ and longitude $2^{\circ} 29.884^{\prime} \mathrm{W}$ with characteristic radial growth. The Wa Municipality is part of the eleven (11) municipal and districts of the Upper West Region of Ghana. It is bordered to the north by the Nadowli and Daffiama-Bussie-Issa Districts, to the east and south by the Wa-East District, to the south by the Sawla-Tuna-Kalba District, and to the East by the Wa-West District. Wa also functions as the administrative capital of the Upper West Region, which shares boundaries with Burkina Faso, and Cote d'Ivoire in the north and west, and the Upper East and Northern regions of Ghana in the east and south, respectively. The town of Wa's population was projected to be 81,725 in 2012 [10].

\subsection{Municipal Solid Waste Management in Wa, Ghana}

The Environmental Health and Sanitation Unit of the Wa Municipal Assembly (EHSU), is the local Authority’s unit that has responsibility to manage MSW in Wa and the entire Municipality. The Authors interviewed the Unit and obtained the following information about MSWM in Wa town:

- Wa produces approximately 20,000 tons of MSW annually, based on $0.45 \mathrm{~kg} /$ capita generation rate.

- This amount of MSW is composed of metals, paper and cardboard, organics (including food and wood wastes), plastics, textiles, inert substances (sand and ashes), and waste electric and electronic equipment.

- About 13,400 tons (68\%) of MSW is collected annually in the town and over $80 \%$ of that collected using the communal container collection system (see Figure 2) while the remaining is collected through house-tohouse system. 


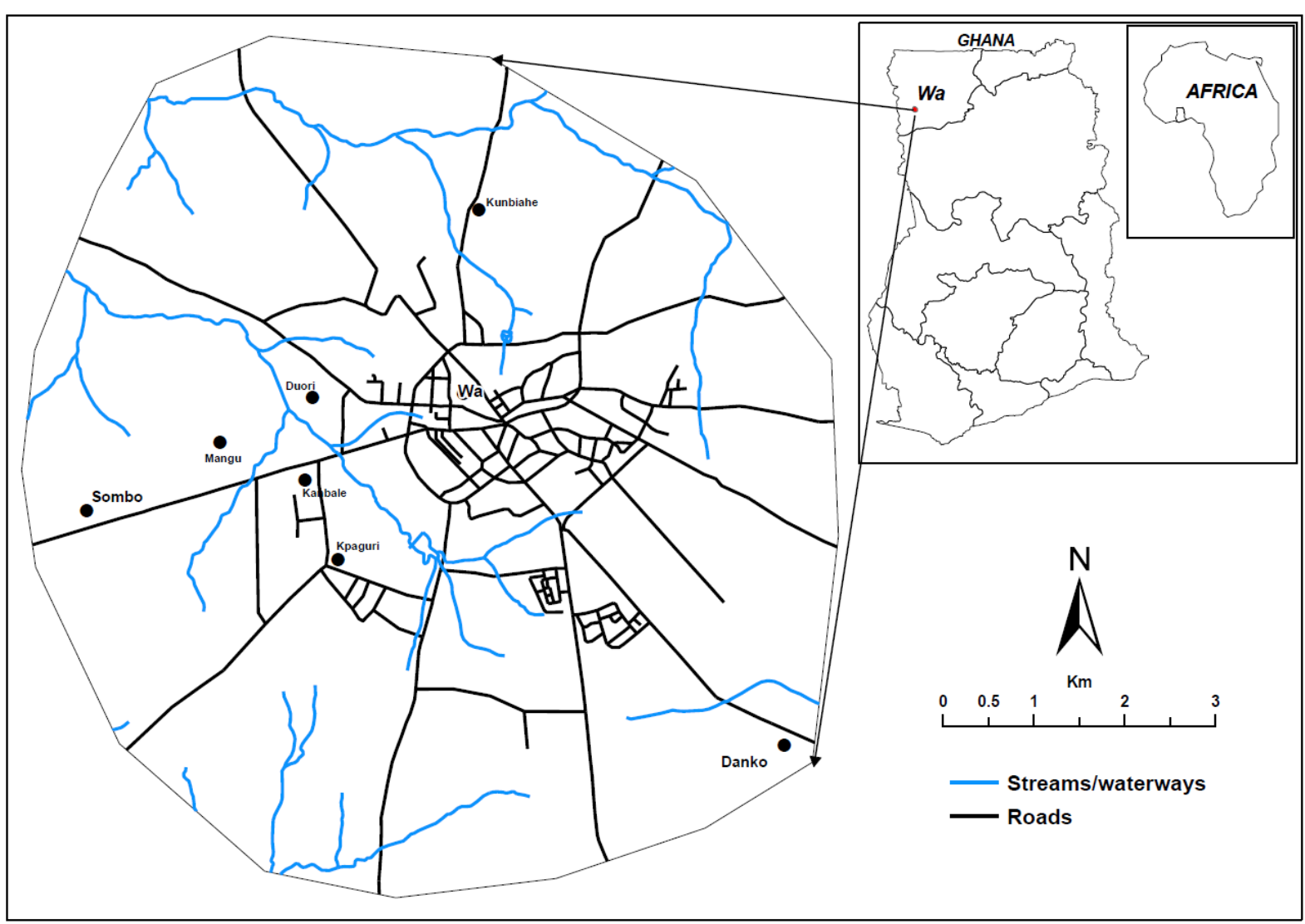

Figure 1. Map of the study area, Wa, Ghana. Insets: Ghana and its geographical location in Africa. Sources: (map by first/ second author; data from Ghana Survey Division topographic maps, 1967, and Ghana at a glance datasets from EPA).

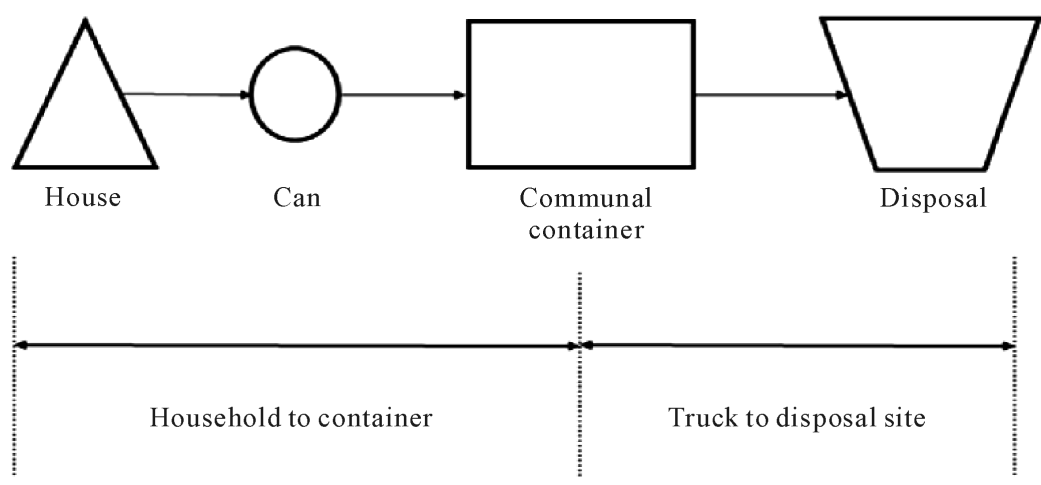

Figure 2. Schematic model of communal container collection system. Source: adapted from Worrell and Vesilind [1].

- The communal containers used have an average capacity of $15 \mathrm{~m}^{3}$ each.

- The EHSU estimates that over 80 communal containers would best serve the municipality but they provided only 37. This few number of containers and inefficient empting of the containers result in heaps of wastes at most of the sites.

- The EHSU have inadequate number of equipment and machinery.

- The over $30 \%$ of uncollected MSW find its way into the environment through littering, burning, and indiscriminate dumping in open spaces and streams/waterways.

- The municipality's final disposal site with an area of about $0.25 \mathrm{~km}^{2}$ is located at Siriyiri, a small community about $5 \mathrm{~km}$ to the west of Wa. This site is not engineered to reduce the risk of environmental pollution. 


\subsection{Drinking Water Sources in Wa, Ghana}

The main source of drinking water for Wa is from the Ghana Water Company Limited (GWCL). Through the Ghana Urban Water Supply strategy, Wa water demand should fully be met by an urban water company like the GWCL. However, a significant proportion of residents depend on boreholes and hand-dug water wells for their domestic water needs due to insufficient water supply. Estimates of current potable water demand by the town is around $15,000 \mathrm{~m}^{3}$ per annum, however, the GWCL is capable of supplying only about $1400 \mathrm{~m}^{3}$ [11]. Thus water rationing is common and residents are forced to rely on alternate sources of water such as boreholes and hand-dug wells to meet water needs.

\section{Data Collection and Analytical Methods}

\subsection{Data Collection}

The data collection for this study was carried out in Wa from June to August 2013 for both MSWCS and drinking water collection sources (i.e. boreholes and hand-dug wells) using a GPS receiver, GPSMAP 62sc, a product of Garmin. The data were then transferred to ArcMap 10.1 (ArcGIS 10.1) software with the aid of DNRGPS software. The layers were projected into WGS 1984 UTM Zone 30N. Relevant attributes (Table 1) were recorded for the MSWCS and drinking water collection sources using data collection sheets. Areas with open, indiscriminate dumps were noted during field visits.

Two hard copy topographic maps for Wa with a scale of 1:50,000 and Ghana National Grid projection were scanned and georeferenced in ArcMap 10.1. The maps were merged and essential features including roads, reservoirs (dams), and communities digitized in ArcMap. The land use polygon and streams/waterways layers were obtained from Center for Remote Sensing and Geographic Information Services (CERSGIS), University of Ghana and these layers were processed in ArcMap to reflect the extent and current conditions in the study area.

\subsection{Analytical Methods}

\subsubsection{Municipal Solid Waste Collection Efficiency and Ground Dumping Analysis}

One of the factors that may impinge on the efficiency of the communal container collection system leading to waste overflows and ground dumping is availability and sufficiency of containers at collection sites. To verify how this may be contributing to MSW collection inefficiency, three scenarios were analyzed; sites 1) with containers and no waste dumped on ground; 2) with containers and waste dumped on ground; and 3) without containers and waste dumped on ground (usually referred to as public dumps or refuse dumps in Ghana). A Thiessen polygons layer was created for the MSWCS layer and the Select tool from Arc Toolbox used to create Thiessen polygons layers for each category. These were then displayed in a map, symbolized differently, and overlaid with the collection sites layer. The total number of sites for each scenario was identified with the Select tool in ArcMap.

\subsubsection{Proximity Analysis: GIS Model for Groundwater Protection Requirement under LI 1827,} Ghana

The Drilling Licence and Groundwater Development Regulations of 2006 (LI 1827) for Ghana has put in place

$\begin{aligned} & \text { Table 1. List of main attributes of MSWCS and drinking water sources used } \\
& \text { for geodatabase construction. }\end{aligned}$
\begin{tabular}{cc}
\hline MSW collection sites attributes & Water collection points attributes \\
\hline Site name (station) & Community name \\
Community name & Construction type (borehole or well) \\
Status of dump site & Ownership (public or private) \\
Availability of container (skip) & $\begin{array}{c}\text { Operation method (hand pump, } \\
\text { mechanized, manual, under construction) }\end{array}$ \\
Waste dump & \\
\hline
\end{tabular}


measures under section 13 (1) and (2) to ensure protection of groundwater from contamination due to borehole development. Section 13 (2) (a) and (b) require drilling contractors to ensure that (LI 1827, p. 5):

"(a) a well fitted with hand pump is sited at minimum distance of thirty meters from the known source of real or potential contamination, (b) a mechanized well is sited at a minimum distance of one hundred meters from the known source of real or potential contamination".

We wanted to ascertain how many boreholes from our data were sited in contravention of these requirements using the MSWCS as known sources of potential contamination. To achieve this, we developed a model (Figure 3) which was utilized to test the minimum distance of 30 meters and 100 meters for hand pump fitted and mechanized boreholes respectively. The input feature classes to the model were the MSW collection sites layer and the boreholes and wells layer. The model includes parameter and expression inputs that allow changing of the distance and the expression for hand pump or mechanized boreholes respectively. It also captures the nearest MSW collection site to each identified borehole and generates the nearest distance between the two using the Near tool from ArcMap.

\subsubsection{Proximity Analysis: Hand-Dug Wells and Surface Water Pollution Risk Mapping}

During our field data collection, we observed indiscriminate dumping of MSW in most stream banks, waterways, and wetlands. It was also noted that most of these areas host hand-dug wells serving as potable water sources. As a result of time and financial constraints during the data collection in Wa, Ghana, the mapping of hand-dug wells was limited to these zones. To analyze the gravity of this dumping, we developed risk ranking criteria (Table 2) which was applied to rank the identified indiscriminate dumping areas from low to high risk of pollution. The identified areas were digitized utilizing imagery base map from ArcMap and the field observations to generate a polygon layer with the ranking criteria as attributes.

\section{Results and Discussion}

\subsection{GIS Map for Municipal Solid Waste Collection/Dump Sites}

A total of 51 MSWCS (37 containers and 14 open dumps) were identified in Wa town through the mapping. The resulting feature layer was employed to develop a MSWCS map (Figure 4). As is obvious from Figure 4, the MSWCS are concentrated within the middle of the town. This pattern may be due to the high density population

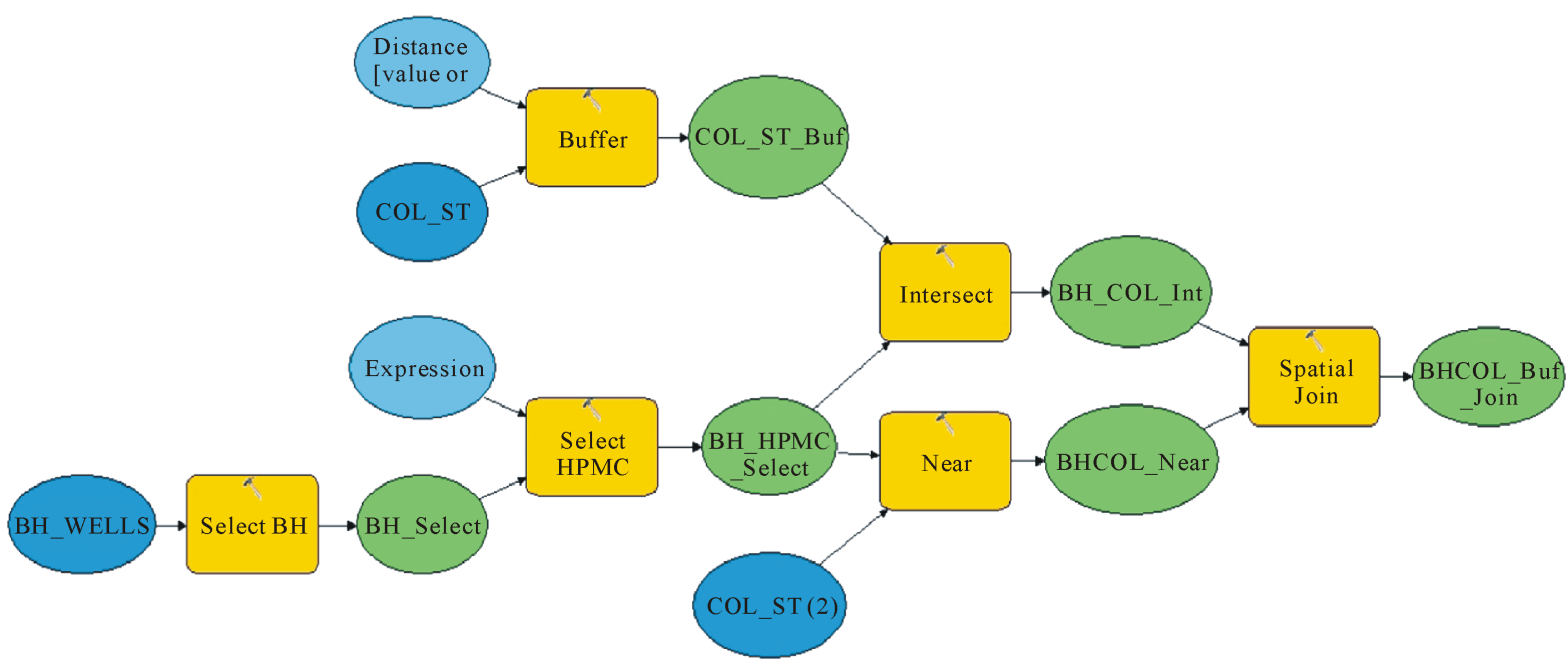

Figure 3. A GIS model to identify boreholes that violates the minimum 30 and 100 meters siting requirement from potential contaminant sources for hand pump fitted and mechanized boreholes respectively. Legend: BH_WELLS = boreholes and wells; COL_ST = MSWCS; Select BH = select boreholes; BH_Select = selected boreholes; HPMC = handpump and mechanized boreholes; BH_HPMC = selected handpump and mechanized boreholes; COL_ST_Buf = MSW collection/ dump sites buffered; BH_COL_Int = intersection of boreholes and collection sites; BH_COL_Near = the nearest distance between an MSWCS and the respective borehole; BHCOL_Buf_Join = boreholes and MSWCS not meeting buffer requirement of LI 1827 joined as a table; Distance = buffer distance; Expression = expression to select handpumps or mechanized boreholes. 
Table 2. Pollution risk ranking criteria.

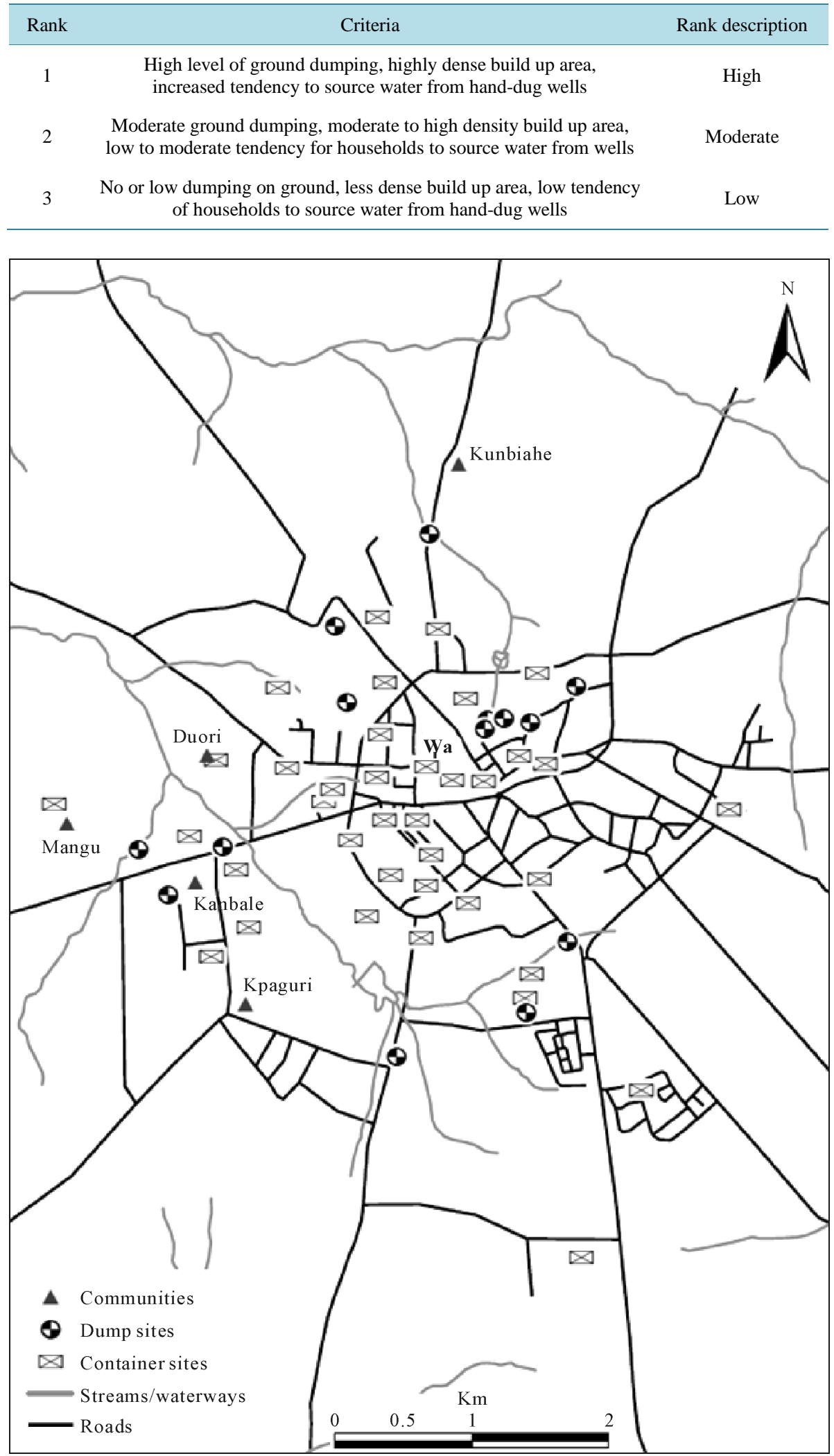

Figure 4. Municipal solid waste collection/dump sites map for Wa, Ghana. 
in town compared to peri-urban areas. Also, it is visible from Figure 4 that from around the middle of town and moving toward west there are virtually no MSWCS. This is expected because this section of the town hosts government buildings including offices, schools, and residential apartments. It is among the few places with house-to-house services that were noted in the field.

MSWCS geodatabase, which can help in planning and management decision making on MSW, is non-existent in Wa. Thus, the creation of this database should be a useful tool toward improving the MSW collection system in Wa Municipality. Further, the accompanying spatial map can be utilized by MSW managers to easily visualize where to direct clean-up programs as well as locate new containers in Wa town [4] [12].

\subsection{Municipal Solid Waste Collection Efficiency and Ground Dumping}

The results of this analysis are shown in Figure 5. Out of the 51 MSWCS mapped, 17 (about 34\%) had containers and no ground dumping of waste, 20 (39\% approximately) had containers with ground dumping of waste, and 14 (nearly 27\%) are without containers with ground dumping. Overall, about 67\% of MSWCS are experiencing ground dumping, which suggests poor MSWM.

The 14 sites experiencing open dumping appear relatively located out of inner town suggesting that the collection system is mostly concentrated in the inner city. Records from the waste managers (EHSU and Zoomlion Ghana Limited) of Wa Municipality showed that 37 container sites were in the town. It may be that these managers are not aware of the dumping going on in most of the 14 sites without containers. This map and its relational database could be a great resource to help these waste managers identify the 14 sites for proper management. Further, the 20 sites with containers and ground dumping are an indication that those sites have inadequate containers and may need additional containers to eliminate or minimize ground dumping. Though we lacked adequate resources to quantify ground dumping during the field survey, it is worth noting that dumped waste range from young to matured and low to relatively higher in volume.

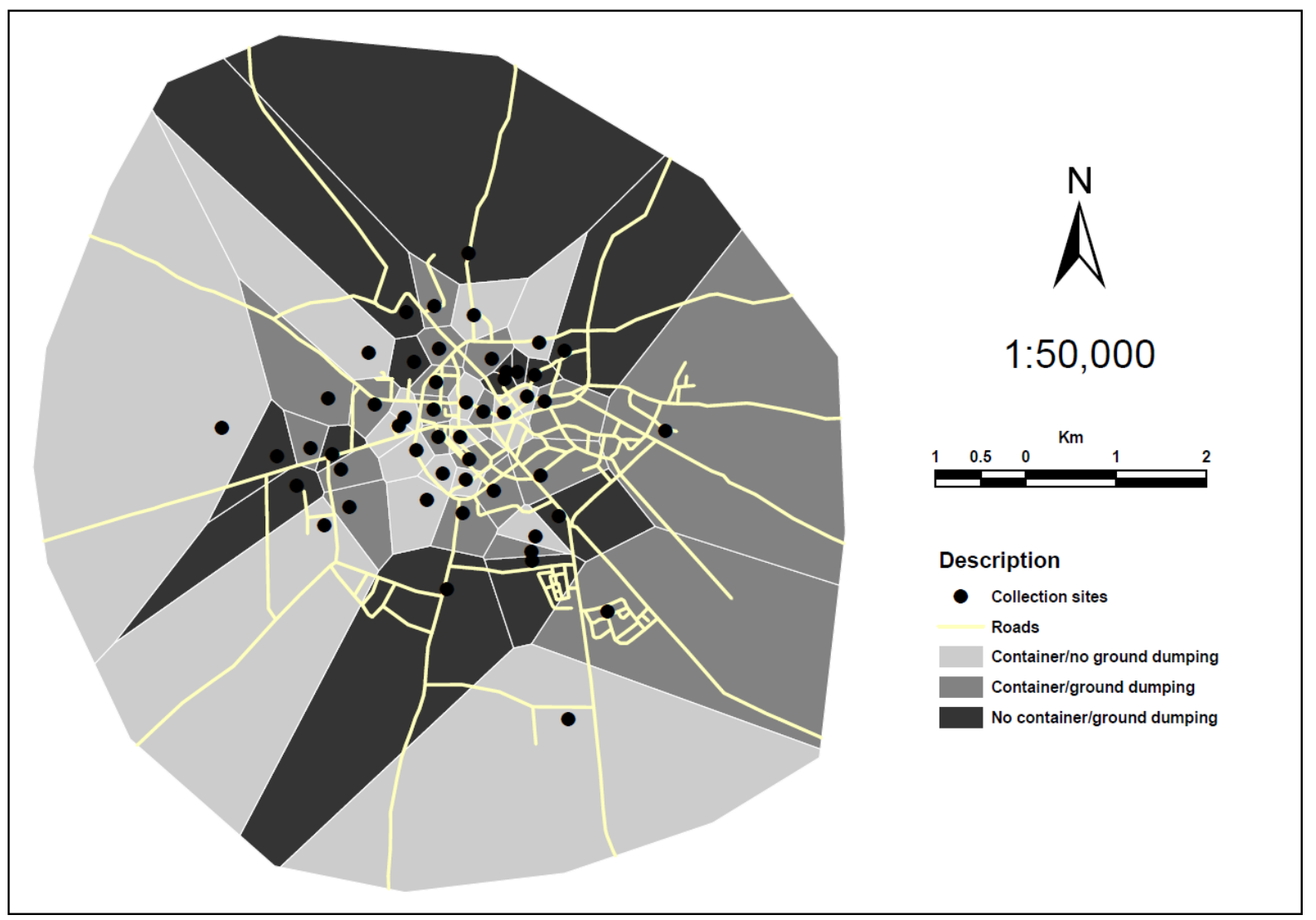

Figure 5. MSWCS showing areas experiencing ground dumping. Theissen polygons describe the hypothetical zone (area) of coverage for each MSWCS. 


\subsection{Proximity Analysis: Boreholes Potentially Violating the Groundwater Protection Requirements under LI 1827}

With the MSWCS as potential contaminant sources, we run the GIS model for the 30 meters minimum distance requirement in the LI 1827 and no result was obtained. This finding suggests that all the handpump boreholes mapped in this study met the minimum 30 meter requirement for siting boreholes with respect to the MSWCS as possible contaminant sources. This implies that the MSWCS may not pollute the handpump water sources per the requirement of LI 1827. However, when the model was run for mechanized boreholes with minimum distance of 100 meters, 15 outputs (24\% of mechanized or $15 \%$ of total boreholes) were generated. These results do not suggest that the affected boreholes must be decommissioned, but to indicate the need for effective MSWM in order to reduce any potential impact on water sources, since the town is not adequately served with potable water by the GWCL. Further, it must be noted that siting of most of these boreholes predates LI 1827 which was promulgated in 2006, and the regulations appear silent on the fate of existing boreholes as regards environmental protection. Hence, these regulations may not be used for enforcement actions on existing boreholes without further directions from the Ghana Water Resources Commission who has the responsibility to implement the law. However, monitoring of the water quality of the identified boreholes may be required to ensure the water meet drinking water quality requirements. This model can be replicated in other parts of Ghana to establish the proximity of boreholes to potential contaminant sites using the appropriate geodatabases. Recommendations can then be made for effective protection of the borehole drinking water sources from impacts of the potential contaminant sources.

\subsection{Proximity Analysis: Surface Water and Hand-Dug Wells Pollution Risk Map}

Results from Figure 6 show high pollution risk zones located within high density built up areas of the town, with no or little open space land. Thus, alternative indiscriminate dumping of MSW within the reserved banks of rivers, streams, wetlands, and watercourses was most likely the practice adopted by nearby residents. Conversely, low density settlement areas were observed to have low indiscriminate dumping and hence were given low pollution risk ranking.

It appears low lying watercourses and stream banks were most patronized for construction of hand-dug wells. As is visible from Figure 6, most of the hand-dug wells mapped were located within these areas. Out of the 18 hand-dug wells, 14 (about 78\%) were found within the pollution risk zones. This suggests that potential pollution of the wells is high, particularly so because of the high water tables and inadequate protection observed for some wells during the field mapping. Using such wells as potable water sources may expose residents to high health risks, although water quality analysis may be required to establish actual pollution. Nevertheless, alternative improved water sources need to be provided for households depending on these wells to prevent any eventuality.

\section{Conclusion and Future Studies}

This study demonstrated how GIS and GPS can be used to enhance decision making on MSW and water management. The creation of GIS geodatabases and maps for Wa town can be utilized by MSW and water resources managers for MSW and water management. From the data collected, an analysis of collection efficiency of the Wa Municipal collection system was conducted based on communal container availability and ground dumping of waste. The spatial relationship between point drinking water sources, surface water, and MSWCS as potential contaminated sites was examined. The findings show high concentration of MSWCS in the inner city of Wa. A significant percentage of container sites characterized by ground dumping and higher number of open dumps in Wa town were also observed, suggesting weakness in the MSW collection system. The findings further indicate significant proximity between MSWCS and drinking water sources and surface water based on model results and the pollution risk map developed.

This study illustrated that MSWM in developing counties could be improved using GIS technology. The approach used for Wa town could be replicated in many other cities and urban towns in Ghana as well as other developing countries with similar MSWM problems to enhance policy and decision making.

The study could not delve into other factors that could decrease collection efficiency such as travel distance and time. Further studies could focus on planning the collection system by considering distance and time factors 


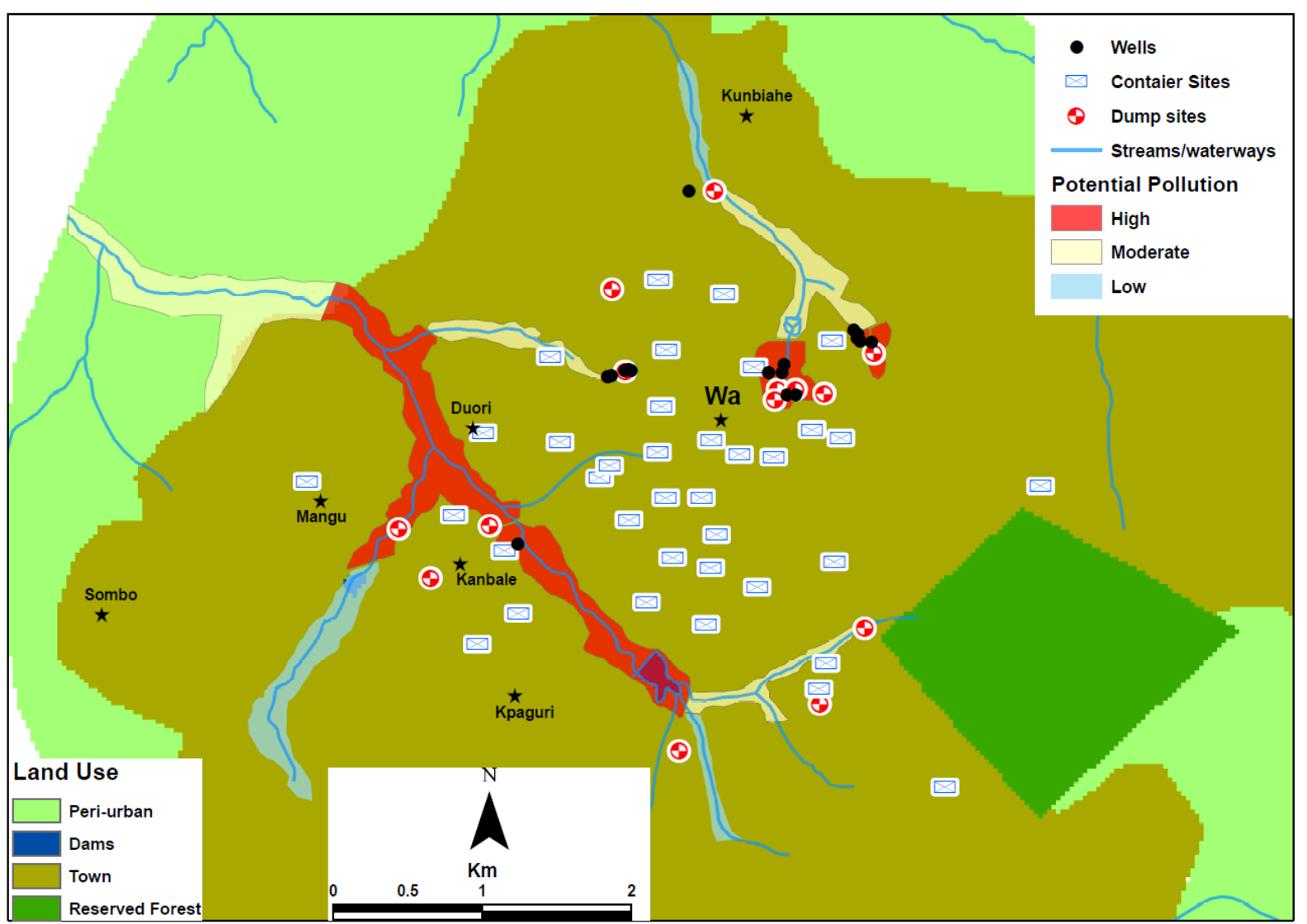

Figure 6. Surface water and pollution risk map for Wa, Ghana.

based on location of containers. The study could not also establish actual contamination of drinking water sources and surface water due to lack of data. Distance (proximity) is one of many factors that could influence pollution of a water resource by a potential contaminant source. Other factors including soil type, topography, land cover, seasons, and population density could have effects on the level of pollution of a water source. Further work could consider some of these factors including water quality assessment of the water resources mapped, to find out actual pollution.

\section{Acknowledgements}

The authors are grateful to Ford Foundation International Fellowships Program (IFP) for funding the field work. We would also like to thank Environmental Health and Sanitation Unit and Zoomlion Ghana Limited, Wa Municipality, Ghana for their assistance during our data collection.

\section{References}

[1] Worrell, W.A. and Vesilind, P.A. (2012) Solid Waste Engineering. 2nd Edition, Cengage Learning, Stamford. http://www.cengagebrain.com/content/worrell62153 143906215301.01 toc.pdf

[2] Tchobanaglous, G., Theisen, H. and Vigil, S. (1993) Integrated Solid Waste Management: Engineering Principles and Management Issues. McGraw-Hill, New York.

[3] Government of Ghana (2010) Environmental Sanitation Policy (Revised 2010). Ministry of Local Government and Rural Development.

[4] Parrot, L., Sotamenou, J. and Dia, B.K. (2009) Municipal Solid Waste Management in Africa: Strategies and Livelihoods in Yaoundé, Cameroon. Waste Management, 29, 986-995. http://dx.doi.org/10.1016/j.wasman.2008.05.005

[5] Hua, H.Z.X. (2003) Application of GIS System into the Management of Municipal Solid Waste. Liaoning Urban and Rural Environmental Science \& Technology, 4, 0-18. 
[6] Khajuria, A., Matsui, T. and Machimura, T. (2011) GIS Application for Estimating the Current Status of Municipal Solid Waste Management System: Case Study of Chandigarh City, India. Our Nature, 9, 26-33.

[7] Sarptas, H., Alpaslan, N. and Dolgen, D. (2005) GIS Supported Solid Waste Management in Coastal Areas. Water Science \& Technology, 51, 213-220.

[8] Chalkias, C. and Lasaridi, K. (2009) A GIS Based Model for the Optimisation of Municipal Solid Waste Collection: The Case Study of Nikea, Athens, Greece. Technology, 1, 11-15.

[9] Osei, F.B., Duker, A.A., Augustijn, E.-W. and Stein, A. (2010) Spatial Dependency of Cholera Prevalence on Potential Cholera Reservoirs in an Urban Area, Kumasi, Ghana. International Journal of Applied Earth Observation and Geoinformation, 12, 331-339. http://dx.doi.org/10.1016/j.jag.2010.04.005

[10] Ghana Statistical Service (2013) Wa Population Projections from 2000-2012. Ghana Statistical Service, Upper West Regional Office, Wa.

[11] Wa Municipal Assembly (n.d.) Performance Review of the 2006-2009 Medium Term Development Plan. Wa Municipal Assembly, Wa.

[12] Sharholy, M., Ahmad, K., Vaishya, R.C. and Gupta, R.D. (2007) Municipal Solid Waste Characteristics and Management in Allahabad, India. Waste Management, 27, 490-496.

http://dx.doi.org/10.1016/j.wasman.2006.03.001 